\title{
Sustainability, resilience, adaptation, and transformation: tensions and plural approaches
}

\author{
$\underline{\text { Laura Zanotti }}^{1}, \underline{\text { Zhao Ma }}^{2}, \underline{\text { Jennifer Lee Johnson }}^{1}$, David R. Johnson $^{3}, \underline{\text { David J. Yu }}^{4}$, Morey Burnham $^{5}$ and Courtney Carothers $^{6}$
}

\begin{abstract}
This article focuses on the debates among resilience, sustainability, adaptation, and transformation concepts. The conceptualization and application of sustainability and resilience thinking in the human-environmental interactions, social-ecological systems, and global environmental change literature remain dominant, which provide a common interdisciplinary and policy language where research in socio-environmental systems can converge. Yet, the lack of clarity and multiplicity among and between these concepts and paradigms allows them to continue to be widely adopted in different sectors of society. Drawing on five case studies from different geographical locations, these diverse applications of resilience, sustainability, adaptation, and transformation are explored from disciplinary and interdisciplinary perspectives. The diversity in the operationalization and use of the concepts and paradigms can result in applications that undermine goals of sustainability or resilience when a particular resource is prioritized over others or is applied in a way that results in inequitable outcomes. Findings from the cases reinforce the importance of being explicit about the spatial, temporal, and institutional boundaries drawn because proposed solutions will vary in their effectiveness if attention to scale, stressors, worldviews, and actors are not addressed holistically. We suggest the ongoing adoption of sustainability, resilience, adaptation, and transformation requires clear and explicit definitions, that draw from decolonized methodologies, goals, in-depth analysis of potential unintended consequences, and situated understanding of how these concepts and the associated paradigms are embedded in particular contexts.
\end{abstract}

Key Words: adaptation; human-environmental interactions; interdisciplinary; resilience; social-ecological systems; sustainability; transformation

\section{INTRODUCTION}

Sustainability and resilience, and the interlinked concepts of adaptation and transformation, dominate proposed solutions to global environmental change (Galaz et al. 2012, Biermann 2014, Saunders 2015). Given the ubiquity of sustainability, resilience, transformation, and adaptation approaches to address ecological crises, economic markets, and human well-being, there is a need to better understand the tensions between these paradigms and concepts by documenting contextualized examples of their applications around the world (Johnson et al. 2018). Such an understanding is critical for assessing trade-offs among sustainability, resilience, transformation, and adaptation as policy goals or program objectives and for identifying opportunities to achieve desired outcomes.

Although sustainability, resilience, adaptation, and transformation are increasingly seen as interrelated, they are distinct paradigms and concepts, with different origins (Johnson et al. 2018). Sustainability, and its more common iteration, sustainable development, emerged as a paradigm in the 1970s and 1980s to address ecological limits, economic growth, and the needs of current and future generations (Meadows et al. 1972, Walker et al. 2006). Sustainable development was defined in the 1987 Brundtland Commission Report and popularized after the 1992 United Nations Conference on Environment and Development. Since then, sustainability and sustainable development continue to be prioritized as goals or outcomes in local to global environmental governance and management. Policy-oriented agendas, such as the 2015 United Nations Sustainable Development Goals, and scholarly frameworks, such as sustainability science, are just a few examples of the varied applications of sustainability and sustainable development (Kates et al. 2001, Griggs et al. 2013). While defying a singular definition, most scholars consider sustainability and sustainable development as frameworks that address one or more of the following aspects of complex systems: environmental stewardship, economic development, political organization, and equity concerns (O'Connor 2006, Foley et al. 2020). Importantly, sustainability and sustainable development also are considered normative paradigms that reflect ideas of intra- and intergenerational justice (Derissen et al. 2011).

Resilience similarly began to develop in the 1970s; however, it emerged as a descriptive paradigm for analyzing disturbance and change; its origins primarily derived from scholarly fields, not policy arenas, including engineering, ecology, and interdisciplinary approaches to complex systems (Holling 1973, Pimm 1984, Gunderson and Holling 2002, Duit et al. 2010, Derissen et al. 2011). Although debates still exist within the literature, resilience theory is commonly understood as an approach that considers the "magnitude of disturbance that can be tolerated before a system moves into a different region of state space and a different set of controls" (Carpenter et al. 2001:766, Gunderson and Holling 2002). However, the application and use of resilience in policy spaces increased throughout the 1980s and 1990s and became pervasive in the 21 st century (Liu et al. 2007, Brown 2014).

\footnotetext{
${ }^{1}$ Department of Anthropology \& Center for the Environment, Purdue University, West Lafayette, IN, USA, ${ }^{2}$ Department of Forestry and Natural Resources \& Center for the Environment, Purdue University, West Lafayette, IN, USA, ${ }^{3}$ School of Industrial Engineering \& Department of Political Science \& Center for the Environment, Purdue University, West Lafayette, IN, USA, ${ }^{4}$ Lyles School of Civil Engineering \& Department of Political Science \& Center for the Environment, Purdue University, West Lafayette, IN, USA, ${ }^{5}$ Idaho State University, Department of Sociology, Social Work, and Criminology, Pocatello, ID, USA, ${ }^{6}$ University of Alaska Fairbanks, College of Fisheries and Ocean Sciences, USA
} 
The increased circulation of resilience as a framework, outcome, or tool has similarly resulted in the proliferation of a wide range of applications and definitions.

Adaptation and transformation, on the other hand, emerged as concepts or attributes nested within sustainability and resilience paradigms, and describe processes for achieving sustainability or resilience outcomes (Walker et al. 2004, Johnson et al. 2018). Whereas both adaptation and transformation typically refer to some kind of adjustment or change, adaptation is often characterized as an incremental change that allows a system to retain its core functions and characteristics (Johnson et al. 2018). Transformation, on the other hand, typically implies a more abrupt change to a new system state (Walker et al. 2004, Pelling et al. 2015). Theoretical debates surrounding adaptation and transformation include whether the two processes are part of the same continuum or if they are distinct (Anderies et al. 2013, Rickards 2013, O'Brien et al. 2015, Johnson et al. 2018).

More broadly, sustainability, resilience, adaptation, and transformation are debated theoretically, empirically, and practically. First, debates focus on the lack of common criteria and operationalization of the paradigms and concepts (Brand and Jax 2007). For example, as resilience shifts from being an analytical framework to an analytical tool, it tends to lose its specificity (Fiksel 2006, Thapa et al. 2010, Park et al. 2013). Because multiple definitions, applications, criteria, and outcomes for sustainability, resilience, adaptation, and transformation exist, some scholars declare them unworkable despite their prevalent adoption (Benson and Craig 2014). Other scholars call for more specific indicators, while some embrace ambiguity as a strength that allows for a shared vocabulary or use of the paradigms and concepts as "boundary objects" that maneuver across interdisciplinary spaces and policy arenas (Clark 2007).

Second, debates also center on the outcomes of sustainability, resilience, adaptation, and transformation processes. Although the normative dimension of sustainability has long been acknowledged (Derissen et al. 2011, Anderies et al. 2013), this has not been the case for resilience, adaptation, and transformation, which has implications for equitable outcomes (Johnson et al. 2018). As such, it is important for any resilience-, adaptation-, or transformation-focused policy, program, or intervention to ask questions such as who the targets are, how the processes occur, and who bears the consequences as results of the policy, program, or intervention (Johnson et al. 2018). Asking these questions would make explicit the implicit normative dimensions of policies, programs, or interventions as well as their desired outcomes (Westley et al. 2011, Leach et al. 2012).

Finally, debates center on the epistemological tensions within, between, and across the concepts of sustainability, resilience, adaptation, and transformation. For example, some scholars, policy makers, and practitioners advocate that addressing the needs for sustainability and resilience requires systems-based thinking and approaches. Other scholars prioritize individual agency, power dynamics, and different ways of knowing (Cote and Nightingale 2012, Brown 2014). Whether resilience or sustainability is the goal or transformation and adaptation the desired processes to achieve those goals is also highly contested. Although some see the paradigms and concepts as complementary and as part of the same spectrum, others envision their simultaneous use as incompatible (Gunderson and Holling 2002, Derissen et al. 2011, Xu et al. 2015). As such, reflecting on the tensions associated with each approach is necessary for minimizing negative outcomes while pursuing desired policy or program goals.

Our objectives in this article as a group of interdisciplinary scholars working at the intersection of these concepts and paradigms are to examine how and in what ways they are deployed or rejected in specific contexts in which we have research experience; to explore what tensions have appeared both within and across these concepts and paradigms; and to describe how policy makers, practitioners, communities, and knowledge holders experience such tensions. In the pages that follow, we draw from our research experiences to illustrate five cases to demonstrate the varying applications of sustainability and resilience paradigms and the adaptation and transformation concepts. The first case, located in northwestern China, details the tensions between different interpretations of one concept, adaptation, and how such tensions determine the sustainability of various adaptation strategies and the resilience of the communities where such adaptations are adopted. The second case, which focuses on forest commons in South Korea, illustrates the tensions between two concepts, transformation and adaption, and demonstrates such tensions can be resolved through proper consideration of system boundaries and the nature of change experienced by a given system. Relatedly, the third case addresses changes in fisheries in Lake Victoria and to this end highlights the tensions between two paradigms, sustainability and resilience, in practitioner and policy contexts. The fourth case centers on decision makers, specifically focused on the Coastal Master Plan in Louisiana, USA, to describe how one application of all those terms and subsequent interpretations of what actions should follow can lead to trade-offs wherein investments in sustainability may come at the expense of resilience. Finally, the fifth case, which draws from a collaborative project with the Iñupiat of Utqiagivik, Alaska, USA, makes the point that the use of these concepts and paradigms can be problematic in the context of differing knowledge systems and worldviews. Together, these cases highlight the normative dimensions of often-assumed descriptive phenomena and in doing so point to implications for equitable outcomes.

\section{CASE STUDIES}

\section{Adaptation to drought and water scarcity in the Loess Plateau Region of China}

This case illustrates how adaptation strategies, motivated by environmental sustainability considerations and developed and implemented at interconnected scales, can interact to create tensions that not only determine the effectiveness and continuous use of the adaptation strategies but shape the resilience of smallholder farming communities that adopted these strategies. Below we first describe the context of this case, the Loess Plateau region of China, and then discuss tensions that arise when the smallholder-led adaptation strategy of planting maize interacts with the state-led adaptation strategy of disseminating drip irrigation to smallholder farming households.

In 2000, the Chinese government initiated the Western Development Program, a long-term effort designed to promote 
sustainable development and reduce the economic gap between China's western and coastal areas (Lai 2002, Grewal and Ahmed 2011). The Loess Plateau, which is in the middle and upper reaches of the Yellow River spanning approximately $647,250 \mathrm{~km}^{2}$ across five provinces, was a primary target. Outside of major urban areas, much of the region's population are smallholder farmers who rely on agriculture for daily food needs and household income. The region's climate is arid and semiarid, and approximately $70 \%$ of its annual precipitation falls between June and September, leaving many crops vulnerable to drought in the early growing season $(\mathrm{Li}$ et al. 2012). Various climate simulations for the region have suggested average annual temperature and drought frequency and intensity will increase, while runoff into the Yellow River will decrease and the timing of rainfall will become less predictable, making the region one of the most agriculturally vulnerable areas in China (Piao et al. 2010, Wu et al. 2014).

As part of the Western Development Program, state actors have implemented various programs to increase agricultural productivity, including promoting drip irrigation, as an adaptation to increasing drought and water scarcity (Zou et al. 2012). The 2011 Central No. 1 Document issued by the Chinese government articulated a plan for investing 4 trillion Yuan (US $\$ 618.8$ billion) in rural water resource projects over the next decade, including using drip irrigation to improve water use efficiency, adaptation to climate change, and environmental sustainability (Yu 2011, Liu et al. 2013). Across the Loess Plateau, local, provincial, and regional governments and state-owned business entities and universities have invested significant financial and technical resources to promote smallholder farmer adoption of drip irrigation. In several villages in the region where we conducted interviews and surveys with farmers, state actors installed drip irrigation systems to replace flood irrigation, free of initial cost to farmers; however, ultimately, they were abandoned by farmers (Burnham et al. 2015). In contrast, the smallholder-led adaptation strategy of planting maize instead of traditionally grown millet and sorghum, was used to simultaneously manage multiple interacting stressors and risks, particularly increasing drought and water scarcity. A detailed examination revealed that each adaptation interacted differently with various social-ecological stressors and risks smallholders faced and other adaptation strategies they used to mitigate these stressors and risks, leading to different effectiveness and continuous use, while also shaping the resilience of the smallholder farming communities.

First, maize was promoted as a drought-tolerant and water-wise crop for promoting agricultural development and environmental sustainability of the region, but it was adopted by smallholder farmers because it has low labor requirements, meaning it allowed households to have time to supplement their household income with off-farm work. Generally, smallholders reported that the market and climatic risks associated with agriculture were too high to be solely dependent on agriculture. Planting maize allowed smallholders to diversify economic activities, which was essential to meeting their household needs and adapting to climate and other social-ecological changes. Second, smallholders planted maize because its price is stable relative to higher value crops, which have highly variable market prices. Thus, planting maize allowed for some degree of protection from market risk. Third, when coupled with plastic mulching, maize tolerates water shortages better than other available crop choices. This was important to smallholders, who identified a need to reduce their vulnerability to drought, early season water shortages, and changing climate and weather patterns. Finally, in a few villages, agricultural irrigation water was polluted by nearby industries and smallholders reported maize was the only crop that grows well enough to be profitable with polluted water. Together, these insights show how maize was used as an adaptation strategy that allows smallholders to manage multiple interacting climatic and nonclimatic stressors, thus contributing to the effectiveness and continued use the adaptation strategy, which in turn strengthened the resilience of smallholder livelihoods by enabling them to manage climatic risks, market fluctuation, and industrial water pollution.

In contrast to the case of planting maize, when the state-led adaptation strategy of drip irrigation began in our study villages, it created tensions with how smallholder farmers structured their livelihoods to manage different forms of risk and uncertainty through planting maize. First, drip irrigation required farmers to spend more time in their fields, which meant they were unable to work off-farm as frequently as they had previously. Second, because of the property rights systems in China and the resulting layout of agricultural fields, the implementation of drip irrigation meant that households had to cooperate with one another to be in their fields at the same time to irrigate crops. Prior to drip irrigation, households were able to make irrigation decisions independently of one another. The forced cooperation exacerbated time demands associated with drip irrigation and meant more missed opportunities for off-farm work. In addition, it contradicted established social norms in study villages in which household agricultural management was not accomplished through day-to-day cooperation with other village households. Finally, in villages with water quality problems, households were reticent to use drip irrigation because polluted water clogged the drip heads, and farmers believed that polluted water would negatively impact the crops when water was delivered directly to the roots of a plant via a drip line. Together, these findings suggest that even though drip irrigation was promoted to address environmental sustainability concerns in the region, the effectiveness of drip irrigation as an adaptation strategy to increasing climate change and water scarcity was compromised because it contradicted the ways that households prioritized their livelihood activities and managed agricultural risks. Indeed, using drip irrigation as an adaptation strategy was seen to reduce smallholder farmers' resilience to external shocks because it forced them to forego off-farm work, created conflict among community members, and exacerbated problems caused by having to irrigate with polluted water.

Overall, this case demonstrates how different adaptation strategies interact with the biophysical, social, economic, political, and institutional contexts in which they are embedded, producing unexpected outcomes. More importantly, this case highlights when an adaptation strategy, i.e., drip irrigation, addresses biophysical stressors while ignoring other interacting stressors, it may produce unintended outcomes such as reduced community resilience and its use may be discontinued. However, when an adaptation strategy is developed and implemented to address multiple stressors and risks simultaneously and complements the formal and informal institutions that shape 
livelihood decision making, i.e., planting maize, it can increase community resilience and livelihood sustainability in the context of ongoing social-ecological change.

\section{Adaption or transformation: changes in the forest commons in South Korea}

This case of forest commons in South Korea illustrates distinctions and tensions between adaptation and transformation. The case is based on the region of Geumsan, South Korea, which is an inland area $\left(576 \mathrm{~km}^{2}\right)$ characterized by a large central flat valley and surrounding mountain ranges with forests. Prior to the 1950 s, 89 forest commons existed in the area, and these had been actively managed by hundreds of villages to source firewood for residential use, e.g., cooking and heating. These long-lasted commons, however, became functionally obsolete by the 1960s in large part because of the advent of fossil fuels. Subsequently, all of the commons underwent major changes. The nature of these changes and the question of whether they should be viewed as adaptations or transformations are the focus of this section. In addition, we discuss how these adaptations or transformations relate to sustainability and resilience.

In general, four patterns of change occurred. In pattern 1, villages conserve their forest commons rather than selling it to outsiders, i.e., forests were turned into community assets that were retained for their intrinsic values. In patterns $2-4$, villages sell some or all of their forest commons to outsiders. However, the outcome of sale varies. In pattern 2 , the sale results in investments to alternative community infrastructures, such as building public roads and bridges, purchasing lands for communal farming, and constructing community centers for shared use. In pattern 3 , the sale results in revenue distributed equally among individual households. In pattern 4 , the sale is accompanied by legal disputes over the property rights and the resulting revenues are distributed unequally among village members.

It is crucial to note that the tensions surrounding whether a socialecological change is a transformation or adaptation and whether transformations are good or bad all depend on how the system boundaries and normative dimensions are defined. For example, if a primary goal is the improvement of household income, the latter two patterns of change can be viewed as desirable transformations. This is because households can invest private gains from the sale of forest commons into alternative private goods, e.g., education or equipment, to increase their income. Further, if the focal scale of analysis is expanded to a larger level, e.g., system boundaries encompassing entire regional society and longer timescale of 100 s of years, all of the four patterns of change can be viewed as gradual adaptations.

Yu et al. (2014) interpret the changes described above as socialecological transformations by drawing on a conceptual system boundary defined by forest commons, social system (a village or villages owning the commons), and the functional relationship between the commons and social system. From the viewpoint of this system boundary, the four patterns of change that took place in the case area all involved fundamental changes to the core system function and characteristics, i.e., the salience of forest commons as the main source of residential energy completely vanished in a relatively short span of time. Further, considering normative dimensions, Yu et al. (2014) classify the observed transformations into two different categories: cooperative and noncooperative transformations. The first two patterns of transformation (conservation of forest and conversion of forest into an alternative community infrastructure) are cooperative in nature, while the latter two patterns (conversion of forest commons into individual gain and legal dispute) are noncooperative. The normative dimension used is the actions that contribute group or social welfare; it is more sustainable in the long run compared to those for private gain only.

Further, these transformations happened because the traditional system (defined by the conceptual system boundary encompassing forest commons, villages owning the commons, and the resource extraction activities) is no longer sustainable. It represents a case of resilience loss within an existing system from structural change in contextual conditions. However, from the perspective of households and their livelihoods, i.e., a narrower system boundary encompassing individual households and their livelihoods, the change in the main source of residential energy and associated transformations in forest commons likely represent increased sustainability and resilience of households to threats to energy supply from locally driven events such as forest destruction by forest fire, diseases, and overharvesting. Thus, this case demonstrates tensions between interpreting empirical results as adaptations and transformation or as sustainability and resilience can be resolved through proper consideration of system boundaries and the nature of change experienced by a given system.

\section{Sustainability undermines resilience in Lake Victoria's contemporary fisheries}

This case of fisheries in Lake Victoria demonstrates that efforts to enact sustainability undermine resilience of this socialecological system as a whole. Lake Victoria is marked by histories of ecological and economic transformation associated with the introduction of the invasive Nile perch (Lates niloticus) in the 1950 s. Prior to the 1950s, the vast majority of all fish were members of an endemic superflock of small and diverse Haplochromine cichlids. In the decades that followed, an estimated 200-300 species of cichlids went extinct by the predatory pressures of the Nile perch and concomitant changes in water quality and habitat availability. By the early 1990s, an extremely profitable industrial processing and export industry for Nile perch fillets was developing in each of the three countries that share this lake, Uganda, Kenya, and Tanzania. Although most of the 30 million eastern Africans who live around Lake Victoria were unable to afford industrially processed fillets, simultaneously, a burgeoning local and regional market for fresh and locally dried Nile perch began to flourish. Approximately two decades later, fisheries scientists and managers declared that Nile perch populations were overfished, and that the entire fishery was unsustainable and destined to collapse in the absence of urgent and drastic managerial interventions.

This case, based on long-term historical and ethnographic research in and around eastern Africa's Lake Victoria, demonstrates that the overwhelming managerial and media focus on declining Nile perch exports as the sustainability crisis in Lake Victoria continues to shape the formation and implementation of fisheries policies that undermine, rather than enhance, the resilience of Lake Victoria's interlinked fisheries ecologies and economies. Although sustainability is widely accepted as a 
normative goal, specific value judgements that shape how sustainability is operationalized are rarely made explicit. Entire species, economies, and segments of societies crucial for maintaining resilient social-ecological systems may be overlooked when sustainability is defined in terms of a single species and commodity form.

The Nile perch export industry and the infrastructures that developed alongside it frame scholarly and popular attention to sustainability in Lake Victoria's fisheries in a particular way. For most fisheries managers and development professionals the Nile perch export industry has become naturalized within Lake Victoria's fisheries ecology and economy. It is the predicted extinction of the Nile perch export industry that now features within Lake Victoria's sustainability crisis narratives, not the hundreds of species of fish that disappeared nor the local fisheries and the availability of locally preferred species and forms of fish, including Nile perch. Formal management of Lake Victoria's fisheries toward sustainability goals has focused on the Nile perch export industry at the expense of managing ecosystem and multispecies local fisheries dynamics more broadly. To attempt to return to Nile perch exports to their peak numbers, eastern African fisheries managers have recently acted under the guidance of European and American technical advisors and donors to enforce prohibitions on forms of fishing, processing, trading, and consuming fish thought to threaten the viability of the Nile perch export trade. Thus, most forms and species of fish that eastern African consumers prefer are now formally illegal (Johnson 2012, Johnson and Robert 2016).

Perhaps paradoxically, these efforts to sustainably manage Lake Victoria's Nile perch export industry undermine the resilience of Lake Victoria's fisheries ecology more broadly. Haplochromine cichlids, while largely ignored by economic development professionals, are crucial for the resilience and recovery of Lake Victoria's fisheries (Johnson 2009, Awiti 2011). The exceptional abilities of these cichlids to adapt to changing aquatic conditions have elevated these fish to a level of scientific notoriety. Because these fish "all look the same" and yet all developed very different food provisioning specializations, scientists say they are “evolution's smoking gun" (Kaufman et al. 1997:26). As populations of large Nile perch have decreased in recent years, Haplochromine populations have experienced a resurgence, and species of these and other fish previously thought to be extinct are now reappearing (Witte et al. 2007, Awiti 2011). Eastern Africans are continuing to consume formally legal and illegal forms of Nile perch, but are beginning, again, to appreciate Haplochromines and a variety of other species for their affordability, exceptional nutritional value, and "sweetness" of flavor (Johnson 2017). Indeed, local and regional consumer demand for fish in Eastern Africa is arguably higher, and the economic benefits of meeting it potentially more lucrative, than ever before. And still, sustaining stocks of large Nile perch for export outside of Africa remains the primary goal of fisheries management in and around Lake Victoria.

By focusing almost exclusively on sustaining stocks of large, exportable Nile perch, policy makers overlook the economic importance of growing local and regional markets for a variety of fish species, and actively work to sustain a less biodiverse and ultimately less resilient fisheries ecology. Attention to the often normative dimensions of sustainability as presently defined and operationalized for Lake Victoria's fisheries opens up opportunities for exploring and ultimately fostering more resilient options, such as the development of multispecies fisheries management plans that prioritize local and regional consumer demand for a variety of species, including Nile perch and Haplochromine cichlids. Perhaps most importantly, attention to the species and economies that are excluded from dominant definitions of fisheries sustainability in Lake Victoria increases the possibility that future attempts to incorporate resilience thinking into fisheries policy and management are more just, equitable, and attentive to historic and contemporary adaptations and transformations in these complex, dynamic, and interlinked ecologies and economies.

\section{Sustainability or resilience in Louisiana's Coastal Master Plan}

A major coastal planning initiative in Louisiana illustrates how, despite decades of discussion about resilience and sustainability, decision makers still conflate these concepts or coopt them in ways at odds with the Western scientific tradition's interpretation of them. It also suggests a trade-off wherein investments in sustainability may come at the expense of resilience.

After hurricanes Katrina and Rita devastated the United States Gulf Coast in 2005, legislators in Louisiana established the state's Coastal Protection and Restoration Authority (CPRA). Its charge is to produce a coastal master plan as a 50-year roadmap "to sustain [their] coastal ecosystem, safeguard coastal populations, and protect vital economic and cultural resources" (Louisiana CPRA 2017). Formally called Louisiana's "Comprehensive Master Plan for a Sustainable Coast," the plan places sustainability squarely in the title. However, it describes the concept by reference to resilience, defining a sustainable system as "characterized by consistent levels of productivity and resilience (the ability to withstand naturally variable conditions and/or recover from disturbances)" (Louisiana CPRA 2012). In fact, the two terms are frequently enjoined: in the 2012 Master Plan's 190-page main text, the words "resilience" or "resilient" are used 10 times. Some form of the word "sustain" appears in the same sentence five of those times. Although recovery from shocks is traditionally a defining element of resilience as a concept, the projects included in the Master Plan are oriented toward risk management and preparation, rather than any consideration of postevent recovery. Consequently, the state's conception of resilience more closely resembles the historical engineering paradigm of the coastal system as having a single desirable equilibrium state; further, resilience is viewed as an analytic framework through which to achieve or measure sustainability. This confusion of terms within the planning documents, and the use of "sustainability" for policy buy-in, show that the call of Benson and Craig (2014), to abandon sustainability in favor of resilience amidst the realities of the Anthropocene, has not yet been heard in Louisiana.

CPRA's own name provides insight into policy makers' goals of protecting existing assets and restoring what has already been lost. Operationally, the Master Plan's primary objectives are two-fold: to protect its population and economic assets from the risk of flooding, and to reduce or reverse the state's land loss crisis (Louisiana has lost over 1900 square miles of land since the 1930s to erosion, sea level rise, and other processes; Couvillion et al. 
2017). The historic tension between flood protection and land restoration is implicitly acknowledged but goes unspoken; levees on the Mississippi River channelize stream flows directly into the Gulf of Mexico, dramatically reducing the frequency of overland flooding but disrupting the sediment deposition processes that originally built and otherwise would replenish the delta (Britsch and Dunbar 1993).

Sustainability, and sustainable development in particular, originally connoted human management of resources in a manner to avoid reductions in services or benefits to future generations. Instead, preservation of the state's economic drivers and key ecosystem services at current levels are essential parts of any proposed coastal management strategies. More ambitious plans framed as transformations, such as the recent Changing Course competition to "re-envision" the Mississippi Delta, are aimed at preserving the viability of current economic activity. The distinction between adaptation and transformation in this competition is a matter of time scale, with winning Changing Course proposals imagining the next 75 to 100 years in the Delta region, as opposed to the Master Plan's 50-year planning horizon (Moffatt \& Nichol 2015). Projects to restore land and protect against flooding are instead described as adaptation measures, adapting to changing external boundary conditions in an attempt to maintain the same conditions on the system interior.

Although the plan couches preservation as both sustainability and resilience, it could perhaps be better described using a different term - resistance, or more generously, reversion - given the range of projects and policies under consideration. In the Coastal Master Plan, Louisiana's concept of sustainability is instead framed as a struggle to maintain resource availability, economic activity, and cultural identities against the threat of external forces. The state's normative perspective is that historic institutions and activities should remain viable in the future; the 2012 and 2017 Master Plans do not use the terms "transform," "transformation," or "transformative" at all. As such, Louisiana implicitly rejects Walker et al.'s (2006) view of transformability as being inherent to resilient social-ecological systems.

When considering more commonly accepted definitions of resilience and sustainability, the Coastal Master Plan shows a clear trade-off between the two, given the major investments in sustaining current conditions at the expense of investing in adaptive capacity that would make coastal communities more resilient. However, the Coastal Master Plan is still an ambitious, data-driven approach to climate change adaptation and natural hazards risk mitigation; many other states are looking at Louisiana's planning process as an exemplary model to emulate. As such, the plan represents an example of Sinclair's (2016) argument that even when resilience in policy is operationally illdefined, it can still be useful in spurring change.

\section{Resilience overlooks self-determination in Utqiaġvik, Alaska}

This case addresses how community members in Utqiagivik, Alaska consider sustainability and resilience as normative, nonlocal paradigms that do not align with Indigenous knowledge systems and worldviews. In this case, we highlight the tensions between how community members envision pathways for the future well-being of Utqiagivik and Western paradigms and concepts meant to achieve the same. In this context, resilience and sustainability paradigms are both perceived as Western scientific concepts and as barriers to well-being and self-determination and not the desired pathways to achieve local goals.

The North Slope Borough (NSB) encompasses eight Iñupiat villages located on the Beaufort and Chukchi seas and in the surrounding inland areas. Because of the villages' predominantly coastal location in the Arctic Circle, questions about resilience and sustainability of Iñupiaq communities and their lands in the NSB are pronounced, particularly in Utqiagivik, the seat of the NSB with over 9000 people (Chapin et al. 2004). A collaborative research project in Utqiagivik initiated in 2010 brought together researchers and community members to analyze women's and men's leadership in a time of pronounced environmental and social change. To this end, at the initial stages of work our research team drew from a social-ecological systems approach to capture the range of social, cultural, and environmental factors that may be contributing to resilience. In order to accommodate for leadership and strength, the two attributes the community wished to be addressed, we adopted a framework that suggests analyzing resilience requires an examination of the following factors: living with uncertainty, nurturing diversity, using different kinds of knowledge for learning, and creating opportunities for selforganization (Berkes 2007, 2017). The goal was to examine and identify the underrepresented social and cultural factors associated with each of these four interrelated processes, acknowledge diverse knowledge systems and worldviews, and draw attention to people in power relationships (see Zanotti et al. 2020).

Our results were striking. We found that for leaders and community members, environmental and climate change were important and critical topics that community members talked about and were worried about, the arena in which resilience and sustainability science and policies were most active in the region. However, climate change was one of several other pronounced changes historically and currently taking place; and many of these other changes were rarely considered in overall analyses of resilience (Moerlein and Carothers 2012, Zanotti et al. 2020). In interviews, it was the brutality and enduring legacy of colonialism, including boarding school experiences, prohibition of spiritually important singing, dancing, and drumming, restriction or prohibition of subsistence activities, Western propertied notions of land, medical testing without consent, and general regulatory and bureaucratic governance norms that were expressed as the primary challenges to Iñupiat well-being and compounded effects of uncertainty and change.

For example, participants told us how the community response to the controversial 1977 International Whaling Commission (IWC) decision demonstrates the way in which community members and local institutions worked to effect change supportive of their well-being in the face of regulations that sought to restrict subsistence hunting in the name of sustainability and resilience. During that year, the IWC issued a moratorium on subsistence bowhead (Balaena mysticetus) whaling in several Alaska Native communities, including Utqiagivik (IWC 1981, Bakalar 2005). In the months following the moratorium, area villages quickly filed a formal objection, formed the Alaska Eskimo Whaling Commission, and submitted several testimonies regarding the importance of bowhead whales (Adams 1982). As a result, the IWC (1981) issued a statement that noted the central 
role of whaling to Iñupiat communities and subsequently lifted the moratorium. The successful reinstatement of subsistence whaling, albeit with quota limitations, could not have occurred without the testimonies and commitment of the Iñupiat who were integral to mobilizing support networks, formulating new institutions based on customary practices, and engaging with Western and Indigenous knowledge systems. This is just one instance of how Iñupiat peoples are responding to the cascading effects of changes as environmental governance regimes challenge subsistence activities foundational to their core beliefs, well-being, and community life, in the name of sustainability or resilience.

Although community members acknowledged that Iñupiat peoples are adjusting institutions and transactional economies to respond to changes in real time, such as the above example demonstrates, paradoxically, neither resilience and sustainability as paradigms nor the social-ecological systems approach resonated (Benessia et al. 2012, Speranza et al. 2014). Community members directed us to critically rethink these frameworks and consider their normative and moral dimensions, which they argued did not adequately recognize unjust historical contexts or best embody Iñupiat worldviews (Cote and Nightengale 2012, Ingalls and Stedman 2016). They questioned: resilience of what? Sustainability for whom? For community members, continuing nested systems that had caused historical and current trauma and violence to their peoples were not considered a promising solution nor the sustenance of practices that had inequitable outcomes.

Instead, participants invited us to critically approach policy oriented or scholarly approaches to resilience and sustainability and to consider the following: (1) how previous practices, such as the IWC ruling, continue to undermine local well-being; and (2) the language of sustainability, adaptive capacity, and resilience are entrenched in Western understandings of solutions that might superficially describe responses to change but do not have the historical context and cosmological grounding to be locally relevant. To counter, community members advocated for decolonial and Indigenous approaches to research that incorporate Iñupiat values (such as knowledge language, sharing, respect for nature) as lenses through which to examine questions about change and continuity. Frameworks proposed by community members gesture toward more relational approaches to human-environment interactions rather than interactionist or system-based approaches that are embodied in paradigms such as social-ecological systems approaches (West et al. 2015, Resilience Science Blog, http://rs.resalliance.org/2015/02/11/ critically-reflecting-on-social-ecological-systems-research/).

Results from this work show the trade-offs that occur when scholars or practitioners adopt sustainability and resilience paradigms, particularly how their applications can erase local frameworks to living well and fail to address historical violence and erasure by more powerful actors. Calling attention to the normative dimensions of both sustainability and resilience paradigms, community members stressed sovereign and selfdetermined futures as orienting frames instead of "sustainable" or "resilient" ones, emphasizing cultural continuity, honoring different generations, and supporting family and community as preferred pathways forward. Moreover, participants emphasized that Iñupiat values, cosmologies, and frameworks are critical for crafting policy outcomes that disrupt dominant discourses and support transformational change that align with pursuits of sovereignty and self-determination.

\section{DISCUSSION}

Case studies from China, South Korea, Lake Victoria in Uganda, and the United States (Louisiana and Alaska) detail the tensions within, between, and across sustainability, resilience, adaptation, and transformation in their applications in academic, policy, or practitioner contexts, and how they may affect or be affected by the complex characteristics of and processes across scales, stressors, boundaries, and knowledge systems. The case study from China, emphasizing tensions associated with adaptation, demonstrates how conceptualizations of risk as emanating from solely biophysical sources is insufficient, and other social, economic, and political factors that interact with a changing climate to create risk and vulnerability must be taken into account for effective policy solutions. Failure is often related to how stateled adaptations contradict livelihood strategies that are designed explicitly or implicitly by smallholder farmers to simultaneously manage multiple forms of risk and uncertainty and the associated social institutions that support farmers (Burnham and Ma 2018). This case argues that adaptation strategies should take into account multiple stressors and risks in order for those strategies to be sustainable over time and simultaneously improve resilience of smallholder farming communities. Furthermore, it demonstrates how a singular focus on one stressor might overlook critical changes in system processes and cross-scale linkages and thus fall short of an adequate assessment of sustainable and resilience outcomes (Domptail et al. 2013, Leenhardt et al. 2015).

Relatedly, taking up the paradigms of sustainability and resilience, the Lake Victoria example illustrates how the overwhelming managerial and media focus on declining Nile perch exports as the sustainability crisis in Uganda's Lake Victoria continues to shape the formation and implementation of fisheries policies that undermine, rather than enhance, the resilience of Lake Victoria's fisheries ecologies and economies. Similar to the China case whereby researchers found exclusive focus on one stressor undermined analyses of adaptation strategies, the Lake Victoria case shows by focusing almost exclusively on sustaining stocks of a single large fish species for export, policy makers often overlook the ecological and economic importance of growing local and regional markets for a variety of species and forms of fish. And by classifying adaptations that foster more biodiverse fisheries as illegal, sustainable fisheries management for Lake Victoria is averse to transformations and ultimately fosters less resilient fisheries. Just as the China case illustrates multiple stressors need to be taken into account, this case demonstrates that attention to the multilevel sustainable solutions that factor in local communities and historical ecological changes increases the possibility that future attempts to incorporate resilience concepts into fisheries policy are more just and equitable than normative applications of sustainability.

Whereas the China and Lake Victoria case caution policy makers against a singular and normative focus in their applications of sustainability, resilience, or adaptation, the Louisiana case details the way in which decision makers' interpretations and uses of sustainability and resilience can problematically diverge from the scientific paradigms of the same concepts. Analysis of Louisiana's "Comprehensive Master Plan for a Sustainable Coast" shows how 
as policy tools or goals, sustainability and resilience gain different meanings as they are used interchangeably and colloquially. In this case, sustainability and resilience move away from their oftcited definitions to instead emphasize risk management and preparation. In this vein, resistance and restoration are proposed as better descriptors of the policy agenda than sustainability or resilience, yet, despite the definitional slippage, we still see resilience and sustainability cited and embraced. Thus, identifying how, in what ways, and in what contexts sustainability and resilience are employed is critical for subsequent applications and outcomes.

From an academic perspective, applying the resilience paradigm as an analytical framework requires clear definitions of system boundaries and normative dimensions of change. Such application contributed to a clearer understanding of whether the four documented patterns of changes in the forest commons in South Korea should be considered adaptations or transformations. Placing emphasis on different spatial-temporal scales shifts the conclusions we can draw about changes sustained in the region and highlights the tensions between adaptation and transformations in achieving desired outcomes. Findings from Utqiagivik, Alaska also illustrate how scholarly concepts like sustainability and resilience are interpreted differently when working with Indigenous knowledge systems. This case demonstrates how sustainability and resilience paradigms are actively critiqued and contested by Alaska Native communities who envision research paradigms and policy makers as setting normative agendas that have harmed, and continue to harm their communities, that do not incorporate their knowledge systems and worldviews, or support their self-determination efforts. Instead, community members in this case advocate for greater awareness of the epistemological and political tensions inherent in combining these paradigms and frameworks with indigenous knowledge systems, questioning sustainability and resilience for whom and at what scale, and changing research and, relatedly, policy approaches to be more inclusive and locally controlled so sustainability goals are not enacted at the expense of the local community. Equally as important in determining desirable futures, is recognizing historical injustices that continue to have long standing effects and legacies today thus suggesting that a decolonizing approach to the paradigms and concepts to sustainability, resilience, adaptation, and transformation is necessary (Zanotti et al. 2020).

As a collection, these case studies reaffirm that there are widespread and multiple approaches to the application or interpretation of sustainability, resilience, transformation, and adaptation paradigms and concepts (Anderies et al. 2004, Brand and Jax 2007). These findings further show how the simultaneous lack of clarity and multiplicity among and between definition and use of these concepts and paradigms allow them to continue to be widely adopted in different sectors of society (Domptail et al. 2013). In this way, our study cases support the observation that scholars, policy makers, practitioners, and community leaders are interested in developing and deploying cross-cutting paradigms and concepts that attend to multiple dimensions of socialecological change. At the same time, the diversity in the operationalization and use of the concepts and paradigms can result in applications that undermine the goals of a sustainability paradigm when a particular resource is prioritized over others, as the Lake Victoria case shows, or are applied in a way that results in inequitable outcomes as the Alaska case study illustrates. Moreover, as the South Korea case demonstrates best, our findings reinforce the importance of being explicit about the boundaries of the paradigms and concepts when considering desired outcomes because they have critical implications on who benefits and at what scales (Carpenter et al. 2001, Lebel et al. 2006). Finally, all cases show, but perhaps the Alaska case depicts most prominently, that there remain epistemological tensions and equity and justice concerns with using sustainability, transformation, adaptation, and resilience concepts and paradigms (Cote and Nightingale 2012, Brown 2014, Olsson et al. 2015).

\section{CONCLUSION}

These results confirm that that researchers, development practitioners, and policy makers continue to use sustainability, resilience, adaptation, and transformation as policy goals and analytical frameworks and do so in a wide array of diverse contexts and situations. The cases suggest that we need to be explicit about the normative dimensions and specific applications of sustainability, resilience, adaptation, and transformation. Outcomes of policies and research will vary depending on the spatial, temporal, and institutional boundaries drawn and proposed solutions will vary in their effectiveness if attention to boundaries, scale, stressors, worldviews, and actors are not addressed holistically. Such analyses that focus on normative and descriptive dimensions of sustainability, resilience, adaptation, and transformation will be crucial for developing future interventions. We find that identifying these tensions is a continued need so that we better assess future planning. As such, our work suggests that the ongoing adoption of sustainability, resilience, adaptation, and transformation requires clear and explicit definitions, that draw from decolonized methodologies, goals, in-depth analysis of potential unintended consequences, and situated understanding of how these concepts and the associated paradigms are embedded in particular contexts.

Responses to this article can be read online at: http://www.ecologyandsociety.org/issues/responses. $\mathrm{php} / 11642$

\section{Acknowledgments:}

This collaborative work was cultivated by the Building Sustainable Communities Signature Area at the Center for the Environment, Discovery Park, Purdue University. The authors benefited from comments from reviewers and participants at the 2017 New Perspectives on Sustainability and Resilience symposium sponsored by the Purdue Center for the Environment, and the 2017 Sustainability and Social Science Research Symposium held in Michigan. Research for the Alaska case was supported by an NSF Office of Polar Programs ASSP Grant \#1304660 and the College of Liberal Arts, Purdue University, Kinley Trust Grant. We would like thank our project advisors, research participants, and the community of Utqiagvik and all the organizations and institutions who opened their homes and lands to us. Finally, we would like to thank the anonymous reviewers who have provided important insights and feedback throughout. 


\section{Data Availability Statement:}

Datalcode sharing is not applicable to this article because no new datalcode were created or analyzed in this study.

\section{LITERATURE CITED}

Adams, J. 1982. History and function of the Alaska Eskimo whaling commission. Pages 9-13 in T. F. Albert, J. J. Kelley, and R. Dronenburg, editors. Proceedings of the First Conference on the Biology of the Bowhead Whale, Balaena Mysticetus: Population Assessment. Alaska Eskimo Whaling Commission, Barrow, Alaska, USA.

Anderies, J. M., C. Folke, B. Walker, and E. Ostrom. 2013. Aligning key concepts for global change policy: robustness, resilience, and sustainability. Ecology and Society 18(2):8. https:// doi.org/10.5751/ES-05178-180208

Anderies, J. M., M. A. Janssen, and E. Ostrom. 2004. A framework to analyze the robustness of social-ecological systems from an institutional perspective. Ecology and Society 9(1):18. https://doi. org/10.5751/ES-00610-090118

Awiti, A. O. 2011. Biological diversity and resilience: lessons from the recovery of cichlid species in Lake Victoria. Ecology and Society 16(1):9. https://doi.org/10.5751/ES-03877-160109

Bakalar, E. M. 2005. Subsistence whaling in the Native village of Barrow: Bringing autonomy to Native Alaskans outside the International Whaling Commission. Brooklyn Journal of International Law 30:601-639.

Benessia A., S. Funtowicz, G. Bradshaw, F. Ferri, E. F. RáezLuna, and C. P. Medina. 2012. Hybridizing sustainability: towards a new praxis for the present human predicament. Sustainability Science 7:75-89. https://doi.org/10.1007/s11625-011-0150-4

Benson, M. H., and R. K. Craig. 2014. The end of sustainability. Society \& Natural Resources 27(7):777-782. https://doi. org/10.1080/08941920.2014.901467

Berkes, F. 2007. Understanding uncertainty and reducing vulnerability: lessons from resilience thinking. Natural Hazards 41(2):283-295. https://doi.org/10.1007/s11069-006-9036-7

Berkes, F. 2017. Environmental governance for the Anthropocene? Social-ecological systems, resilience, and collaborative learning. Sustainability 9(7):1232. https://doi. org/10.3390/su9071232

Biermann, F. 2014. Earth system governance: world politics in the Anthropocene. MIT Press, Boston, Massachusetts, USA. https:// doi.org/10.7551/mitpress/9780262028226.001.0001

Brand, F. S., and K. Jax. 2007. Focusing the meaning(s) of resilience: resilience as a descriptive concept and a boundary object. Ecology and Society 12(1):23. https://doi.org/10.5751/ ES-02029-120123

Britsch, L. D., and J. B. Dunbar. 1993. Land loss rates: Louisiana coastal plain. Journal of Coastal Research 9(2):324-338.

Brown, K. 2014. Global environmental change I: a social turn for resilience? Progress in Human Geography 38(1):107-117. https:// doi.org/10.1177/0309132513498837
Burnham, M., and Z. Ma. 2018. Multi-scalar pathways to smallholder adaptation. World Development 108:249-262. https:// doi.org/10.1016/j.worlddev.2017.08.005

Burnham, M., Z. Ma, and D. Zhu. 2015. The human dimensions of water saving irrigation: lessons learned from Chinese smallholder farmers. Agriculture and Human Values 32:347-360. https://doi.org/10.1007/s10460-014-9565-8

Carpenter, S., B. Walker, J. M. Anderies, and N. Abel. 2001. From metaphor to measurement: resilience of what to what? Ecosystems 4(8):765-781. https://doi.org/10.1007/s10021-001-0045-9

Chapin, F. S., G. Peterson, F. Berkes, T. V. Callaghan, P. Angelstam, M. Apps, C. Beier, Y. Bergeron, A.-S. Crépin, K. Danell, T. Elmqvist, C. Folke, B. Forbes, N. Fresco, G. Juday, J. Niemelä, A. Shvidenko, and G. Whiteman. 2004. Resilience and vulnerability of northern regions to social and environmental change. AMBIO 33(6):344-349. https://doi.org/10.1579/0044-7447-33.6.344

Clark, W. C. 2007. Sustainability science: a room of its own. Proceedings of the National Academy of Sciences of the United States of America 104(6):1737-1738. https://doi.org/10.1073/ pnas.0611291104

Cote, M., and A. J. Nightingale. 2012. Resilience thinking meets social theory: situating social change in social-ecological systems (SES) research. Progress in Human Geography 36(4):475-489. https://doi.org/10.1177/0309132511425708

Couvillion, B. R., H. Beck, D. Schoolmaster, and M. Fischer. 2017. Land area change in coastal Louisiana (1932 to 2016). Scientific Investigations Map 3381. United States Geological Survey, Reston, Virginia, USA. https://doi.org/10.3133/sim3381

Derissen, S., M. F. Quaas, and S. Baumgärtner. 2011. The relationship between resilience and sustainability of ecologicaleconomic systems. Ecological Economics 70(6):1121-1128. https:// doi.org/10.1016/j.ecolecon.2011.01.003

Domptail, S., M. H. Easdale, and Yuerlita. 2013. Managing socioecological systems to achieve sustainability: A study of resilience and robustness. Environmental Policy and Governance 23(1):30-45. https://doi.org/10.1002/eet.1604

Duit, A., V. Galaz, and J. Ebbesson. 2010. Governance, complexity, and resilience. Global Environmental Change 20:363-368. https://doi.org/10.1016/j.gloenvcha.2010.04.006

Fiksel, J. 2006. Sustainability and resilience: toward a systems approach. Sustainability: Science, Practice, \& Policy 2(2):14-21. https://doi.org/10.1080/15487733.2006.11907980

Foley, P., E. Pinkerton, M. G. Wiber, and R. L. Stephenson. 2020. Full-spectrum sustainability: an alternative to fisheries management panaceas. Ecology and Society 25(2):1. https://doi. org/10.5751/ES-11509-250201

Galaz, V., F. Biermann, C. Folke, M. Nilsson, and P. Olsson. 2012. Global environmental governance and planetary boundaries: an introduction. Ecological Economics 81:1-3. https://doi.org/10.1016/ j.ecolecon.2012.02.023

Grewal, B. S., and A. D. Ahmed. 2011. Is China's western regional development strategy on track? An assessment. Journal of 
Contemporary China 20(69):161-181. https://doi. org/10.1080/10670564.2011.541626

Griggs, D., M. Stafford-Smith, O. Gaffney, J. Rockström, M. C. Öhman, P. Shyamsundar, W. Steffen, G. Glaser, N. Kanie, and I. Noble. 2013. Policy: sustainable development goals for people and planet. Nature 495:305-307. https://doi.org/10.1038/495305a

Gunderson, L. H., and C. S. Holling. 2002. Panarchy: understanding transformations in systems of humans and nature. Island, Washington, D.C., USA.

Holling, C. S. 1973. Resilience and stability of ecological systems. Annual Review of Ecology and Systematics 4:1-23. https://doi. org/10.1146/annurev.es.04.110173.000245

Ingalls, M. L., and R. C. Stedman. 2016. The power problematic: exploring the uncertain terrains of political ecology and the resilience framework. Ecology and Society 21(1):6. https://doi. org/10.5751/ES-08124-210106

International Whaling Commission. 1981. Report of the Special Working Group of the Technical Committee Concerning Management Principles and Development of Guidelines about Whaling for Subsistence by Aborigines. Doc. IWC/33/14. International Whaling Commission, Cambridge, UK.

Johnson, J. 2009. Climate change and fishery sustainability in Lake Victoria. African Journal of Tropical Hydrobiology and Fisheries 12:31-36. https://doi.org/10.4314/ajthf.v12i1.57368

Johnson, J. L. 2012. Managerial technologies, [il]legal livelihoods and the forgotten consumers of Africa's largest freshwater fishery. Pages 248-270 in T. Falola and E. Brownell, editors. Landscape and environment in colonial and postcolonial Africa. Routledge, New York, New York, USA.

Johnson, J. L. 2017. Eating and existence on an island in Southern Uganda. Comparative Studies of South Asia, Africa and the Middle East 37(1):2-23. https://doi.org/10.1215/1089201x-3821273

Johnson, J. L., and B. Robert. 2016. Working with fish in the shadows of sustainability. Pages 195-233 in J. Murton, D. Bavington, and C. Dokis, editors. Subsistence under capitalism: historical and contemporary perspectives. Rural, Wildland, and Resource Studies Series 4. McGill-Queen's University Press, Montréal, Québec, Canada.

Johnson, J. L., L. Zanotti, Z. Ma, D. J. Yu, D. R. Johnson, A. Kirkham, and C. Carothers. 2018. Interplays of sustainability, resilience, adaptation and transformation. Pages 3-25 in W. Leal Filho, R. W. Marans, and J. Callewaert, editors. Handbook of sustainability and social science research. Springer, Cham, Switzerland. https://doi.org/10.1007/978-3-319-67122-2

Kates, R. W., W. C. Clark, R. Corell, J. M. Hall, C. C. Jaeger, I. Lowe, J. J. McCarthy, H. J. Schellnhuber, B. Bolin, N. M. Dickson, et al. 2001. Sustainability science. Science 292(5517):641-642. https://doi.org/10.1002/9781118786352.wbieg0279

Kaufman, L. S., L. J. Chapman, and C. A. Chapman. 1997. Evolution in fast forward: haplochromine fishes of the Lake Victoria region. Endeavour 21(1):23-30. https://doi.org/10.1016/ $\underline{\text { S0160-9327(96)10034-X }}$
Lai, H. 2002. China's Western development program: its rational, implementation, and prospects. Modern China 28(4):432-466. https://doi.org/10.1177/009770040202800402

Leach, M., J. Rockström, P. Raskin, I. Scoones, A. C. Stirling, A. Smith, J. Thompson, E. Millstone, A. Ely, E. Arond, C. Folke, and P. Olsson. 2012. Transforming innovation for sustainability. Ecology and Society 17(2):11. https://doi.org/10.5751/ES-04933-170211

Lebel, L., J. M. Anderies, B. Campbell, C. Folke, S. HatfieldDodds, T. P. Hughes, and J. Wilson. 2006. Governance and the capacity to manage resilience in regional social-ecological systems. Ecology and Society 11(1):19. https://doi.org/10.5751/ ES-01606-110119

Leenhardt, P., L. Teneva, S. Kininmonth, E. Darling, S. Cooley, and J. Claudet. 2015. Challenges, insights and perspectives associated with using social-ecological science for marine conservation. Ocean and Coastal Management 115:49-60. https:// doi.org/10.1016/j.ocecoaman.2015.04.018

Li, Z., F. Zheng, W. Liu, and D. C. Flanagan. 2010. Spatial distribution and temporal trends of extreme temperature and precipitation events on the Loess Plateau of China during 1961-2007. Quaternary International 226(1-2):92-100. https://doi. org/10.1016/j.quaint.2010.03.003

Liu, J., T. Dietz, S. R. Carpenter, C. Folke, M. Alberti, C. L. Redman, S. H. Schneider, E. Ostrom, A. N. Pell, J. Lubchenco, W. W. Taylor, Z. Ouyang, P. Deadman, T. Kratz, and W. Provencher. 2007. Coupled human and natural systems. $A M B I O$ 36(8):639-649. https://doi.org/10.1579/0044-7447(2007)36[639: CHANS]2.0.CO;2

Liu, J., C. Zang, S. Tian, J. Liu, H. Yang, S. Jia, L. You, B. Liu, M. Zhang. 2013. Water conservancy projects in China: achievements, challenges and way forward. Global Environmental Change 23(3):633-643. https://doi.org/10.1016/j.gloenvcha.2013.02.002

Louisiana Coastal Protection and Restoration Authority (CPRA). 2012. Louisiana's comprehensive master plan for a sustainable coast. Louisiana Coastal Protection and Restoration Authority, Baton Rouge, Louisiana, USA.

Louisiana Coastal Protection and Restoration Authority (CPRA). 2017. Louisiana's comprehensive master plan for a sustainable coast. Louisiana Coastal Protection and Restoration Authority, Baton Rouge, Louisiana, USA.

Meadows, D. H., D. L. Meadows, J. Randers, and W. W. Behrens. 1972. The limits to growth: a report for the Club of Rome's Project on the Predicament of Mankind. Universal Books, New York, New York, USA. https://doi.org/10.1349/ddlp.1

Moerlein, K. J., and C. Carothers. 2012. Total environment of change: impacts of climate change and social transitions on subsistence fisheries in northwest Alaska. Ecology and Society 17 (1):10. https://doi.org/10.5751/ES-04543-170110

Moffatt \& Nichol. 2015. The giving delta: changing course Phase 1. Moffatt \& Nichol, New Orleans, Louisiana, USA.

O'Brien, K., S. Eriksen, T. H. Inderberg, and L. Sygna. 2015. Climate change and development: adaptation through transformation. Chapter 15 in T. H. Inderberg, S. Eriksen, K. 
O'Brien, and L. Sygna, editors. Climate change adaptation and development: transforming paradigms and practices. Routledge, New York, New York, USA.

O'Connor, M. 2006. The "Four Spheres" framework for sustainability. Ecological Complexity 3(4):285-292. https://doi. org/10.1016/j.ecocom.2007.02.002

Olsson, L., A. Jerneck, H. Thoren, J. Persson, and D. O'Byrne. 2015. Why resilience is unappealing to social science: theoretical and empirical investigations of the scientific use of resilience. Science Advances 1(4):e1400217. https://doi.org/10.1126/sciadv.1400217

Park, J., T. P. Seager, P. S. C. Rao, M. Convertino, and I. Linkov. 2013. Integrating risk and resilience approaches to catastrophe management in engineering systems. Risk Analysis 33:356-367. https://doi.org/10.1111/j.1539-6924.2012.01885.x

Pelling, M., K. O'Brien, and D. Matyas. 2015. Adaptation and transformation. Climatic Change 133:113-127. https://doi. org/10.1007/s10584-014-1303-0

Piao, S., P. Ciais, Y. Huang, Z. Shen, S. Peng, J. Li, L. Zhou, H. Liu, Y. Ma, Y. Ding, et al. 2010. The impacts of climate change on water resources and agriculture in China. Nature 467:43-51. https://doi.org/10.1038/nature09364

Pimm, S. L. 1984. The complexity and stability of ecosystems. Nature 307(5949):321-326. https://doi.org/10.1038/307321a0

Rickards, L. 2013. Transformation is adaptation. Nature Climate Change 3:690. https://doi.org/10.1038/nclimate1933

Saunders, F. P. 2015. Planetary boundaries: at the threshold... again: sustainable development ideas and politics. Environment, Development and Sustainability 17(4):823-835. https://doi. org/10.1007/s10668-014-9577-y

Sinclair, S. J. 2016. Getting the best out of "resilience" as a conservation policy goal: a response to Newton. Conservation Letters 9(5):390-391. https://doi.org/10.1111/conl.12287

Speranza, C. I., U. Wiesmann, and S. Rist. 2014. An indicator framework for assessing livelihood resilience in the context of social-ecological dynamics. Global Environmental Change 28:109-119. https://doi.org/10.1016/j.gloenvcha.2014.06.005

Thapa, S., F. Marshall, and S. Stagl. 2010. Understanding periurban sustainability: the role of the resilience approach. STEPS Working Paper 38. STEPS Centre, Brighton, UK. [online] URL: https://www.fsnnetwork.org/sites/default/files/resilience_approach_web. pdf

Walker, B., C. S. Holling, S. R. Carpenter, and A. Kinzig. 2004. Resilience, adaptability and transformability in social-ecological systems. Ecology and Society 9(2):5. https://doi.org/10.5751/ ES-00650-090205

Walker, B., D. Salt, and W. Reid. 2006. Resilience thinking: sustaining people and ecosystems in a changing world. Island, Washington, D.C., USA.

Westley, F., P. Olsson, C. Folke, T. Homer-Dixon, H. Vredenburg, D. Loorbach, J. Thompson, M. Nilsson, E. Lambin, J. Sendzimir, B. Banerjee, V. Galaz, and S. van der Leeuw. 2011. Tipping toward sustainability: emerging pathways of transformation. AMBIO 40 (7):762. https://doi.org/10.1007/s13280-011-0186-9
Witte, F., J. H. Wanink, M. Kishe-Machumu, O. C. Mkumbo, P. C. Goudswaard, and O. Seehausen. 2007. Differential decline and recovery of haplochromine trophic groups in the Mwanza Gulf of Lake Victoria. Aquatic Ecosystem Health \& Management 10 (4):416-433. https://doi.org/10.1080/14634980701709410

Wu, W., P. H. Verburg, and H. Tang. 2014. Climate change and the food production system: impacts and adaptation in China. Regional Environmental Change 14(1):1-5. https://doi.org/10.1007/ s10113-013-0528-1

Xu, L., D. Marinova, and X. Guo. 2015. Resilience thinking: a renewed system approach for sustainability science. Sustainability Science 10(1):123-138. https://doi.org/10.1007/s11625-014-0274-4

Yu, C. 2011. China's water crisis needs more than words. Nature 470:307. https://doi.org/10.1038/470307a

Yu, D. J., J. M. Anderies, D. Lee, and I. Perez. 2014. Transformation of resource management institutions under globalization: the case of songgye community forests in South Korea. Ecology and Society 19(2):1-25. https://doi.org/10.5751/ ES-06135-190202

Zanotti, L., C. Carothers, C. A. Apok, S. Huang, J. Coleman, and C. Ambrozek. 2020. Political ecology and decolonial research: coproduction with the Iñupiat in Utqiagivik. Journal of Political Ecology 27(1):43-66. https://doi.org/10.2458/v27i1.23335

Zou, X., Y. Li, Q. Gao, and Y. Wan. 2012. How water saving irrigation contributes to climate change resilience-a case study of practices in China. Mitigation and Adaptation Strategies for Global Change 17(2):111-132. https://doi.org/10.1007/s11027-011-9316-8 